\title{
第40回地域農林経済学会大会記念講演
}

\section{SUSTAINABLE AGRICALTURAL DEVELOPMENT: IMPLICATIONS FOR AGRICULTURAL EDUCATION AND RESEARCH}

\author{
John W. Longworth \\ The University of Queensland, Brisbane, Australia
}

On a world-wide basis, the number of university courses in agricultural science and related disciplines such as agricultural economics and farm manangement increased dramatically in the 1950 to 19. 90 period. One of the most important factors influencing this development was the perceived need to enlist the assistance of modem science to solve the world food problem. That is, for the last four decades, agricultural education at the tertiary level has been primarily orientated to increasing food production. Consequently, a large proportion of the human capital (researchers) creatcd by these educational programs has been used to address productionrelated problems. The result has been a massive increase in agricultural productivity. But these gains have not been achieved without putting great pressure on the environment.

Gradually, the negative impacts of the gains in agricultural productivity (soil degradation, salination, species extinctions, etc.) have become increa singly obvious and important. The recent growing public awareness of the need to develop sustainable production systems has given respectability to ideas which previously were dismissed by many production oriented educators and scientists as counterproductive.

University programs have been slow to adjust to the new reality. While the intellectual challenges associated with "making two ears of corn grow where one grew before" inspired agricultural scientists in the mid 20th Century, the challenge for the 21st Century is how to ensure that the hard won gains of the last 40 years can be maintained and even developed further within sustainable farming systems.

Two fundamental changes need to be widely implemented if mainstream tertiary agricultural eduction and research is to answer the sustainability challenge.

First, undergraduate and postgraduate prog. rams in agricultural science must provide a greater awareness of the long-term costs and benefits of technological and social change. Sustainability refers not only to physical environments but to social (and economic) environments as well. Indeed, it is the conflict between these two aspects of sustainability which creates most of the fundamental problems facing Third World agriculture today.

Secondly, researchers need to be taught how to identify the real problems and to be rewarded for tackling these issues. So much agricultural research over the last 40 years has been misdirected. Most decisions about precisely what research will be undertaken are in the hands of the researchers themselves. Their concepts of "what counts" towards their own professional advancement greatly influences exactly what research is undertaken. We need to question whether the traditional personal reward struc tures for agricultural scientists are consistent with the social goal of working towards long-term sustainable agricultural systems.

\section{The Knowledge Explosion: The Need for a New Strategy}

The amount of scientific information relevant to agriculture has expanded greatly in the last 40 
years. No longer is it possible to "cover everything" even in relatively highly specialized university programs. A new strategy for training agricultural scientists is required.

Some would advocate the holistic agricultural systems approach. While there is great merit in a systems approach to research (see Nagy and San$\operatorname{ders}(1990)$ ), it is not the answer in regard to agricultural education. Students still need a rigorous disciplinary base on which to build. The question is which disciplines and what degree of depth in each is required.

The traditional agricultural science program has been built on the basic physical and biological science disciplines. Exposure to the social and behavioural sciences has been minimal. These traditional programs, for the most part, do not place sufficient emphasis on the social science concepts relevant to analyzing sustainable development issues.

A new educational strategy is required which retains a strong disciplinary basis but, at the same time, inculcates a different philosophy and set of values. The next generation of agricultural scientists must place a much higher value on the need for agricultural technology which can increase productivity within a production system which is sustainable in social and economic tcrms as well as in a technological sense.

\section{Sustainable Development: Some of the Broard Issues}

Sustainable development is a more complicated concept than many advocates of the idea acknowledge. In an excellent brief review of the issues associated with the concept of sustainable development, Veeman (1989) suggests there are three interwoven aspects to be considered : a growth component, a distributional component and an environmental component.

\subsection{Growth component}

Early theories about economic growth placed great emphasis on the accumulation of physical capital and the need for a high marginal rate of savings to finance capital accumulation.
Gradually, the emphasis shifted to acknowledge the contribution of human capital formation to the growth process. The recent emphasis on sustainable development has added two more dimensions, namely, the need to give greater weight to the intertemporal and intergenerational implications of economic growth and the role of natural resources in longterm economic growth.

There are two major difficulties in the traditional approach to analyzing economic growth which the recent sustainability debate has moved to centre stage.

The first concerns the hypothesis that the role of natural resources in economic progress declines as economies become more industrialized. There are at least two compelling reasons why this hypothesis should be rejected. First, much of the natural resource input to human well-being is not included in the conventional indicators of growth such as changes in GNP. Secondly, the income elasticity of demand for the (mostly non-market) services provided by natural resources appears to be extremely high. That is, from both the supply side and the demand perspective, natural resources tend to become increasingly important as growth progresses.

The second major difficulty with conventional discussions about growth which the sustainability debate has highlighted is that national accounting measurement procedures do not allow for the dep reciation/deterioration in natural resource assets. National income (and hence economic growth) measurements, therefore, may seriously overstate the true rate of improvement in the welfare of the society.

Economic progress, especially in the Third World but also in wealthy countries, makes sustainable development possible. Yet, paradoxically, the growth aspect of sustainable development is frequently in conflict with the other two aspects of sustainable development (i.e. the distributional and the environmental aspects).

Agricultural students need to be educated to appreciate the complexity of this paradox. They must be given a conceptual framework and a set of analy. tical tools/skills with which to resolve this conflict 
on a case-by-case basis. Traditional agricultural science courses have concentrated on scientific and technological approaches to increasing productivity and hence growth. They have not developed human cap ital which can recognize and contribute to the solution of the growth/sustainainability paradox. Hence, the emergence of a plethora of environmental science courses. Agricultural scientists have become the "bad guys" trained to exploit the natural environmont in the name of agricultural development. Environmental scientists are the "good guys" trained to protect the environment.

Agricultural educational programs for the future must seek the middle ground. They must be designed to train people who can devide agricultural production methods which both contribute to increas ed productivity (growth) and satisfy the distribu tional and environmental aspects of sustainable development.

\subsection{Distributional component}

Economic growth only becomes economic development when the benefits growth are widely distributed.

A major debate has emerged in the last decade about whether agricultural research projects should be screened for distributional consequences. Research, for example, which promises to lead to significant growth (increased agricultural productivity) but which will benefit larger wealthier landholders rather than the poorer smallholderd, is seen as in. appropriate research. This raises at least two que stions.

First, can research administrators identify such "inappropriate" research ex ante with any certainty? Research originally conceived as inappropriate on "distributional" grounds may become most appropriate ex post. As in the case examined by Yee and Longworth (1985), this could occur because the advances achieved eventually prove not to be biased either towards wealthy/larger producers or towards certain factors of production (e.g. capital) because conditions in the factor markets (and hence factor rewards) change during the gestation of the research.
Secondly and more fundamentally, should agricultural research be used to solve distributional problems in the rural sector? Research policy is an extremely blunt instrument with which to attack such problems. Other more direct policy measures such as tax reform and land reform are more appropriate.

This is not the place to pursue this debate. However, it illustrates the critical need for agricultural educators who are training future researchers to acquaint their students with these broader issues of research policy. While the need to develop appropriate technology in a technological sense is relatively staightforward, the broadening of the definition of appropriate technology to encompass its distributional consequences raises a more complicated set of issues. Most agricultural scientists are not being trained to understand or to address these distributional aspects.

\subsection{Environmental component}

Economists have a long tradition of tackling environmentai issues rather differently from biological scientists. The concepts of externalities, property rights and optimum rates of depletion are but three of the many ideas which economists have developed to help analyze environmental issues. Perhaps the biggest difference between the econo mists' paradigm and that of most biological scientists, is that economists do not perceive natural resources as a fixed quantum with a predetermined finite capacity to satisify the needs of mankind.

Instead, economists stress the ingenuity of man. Our capacity to adjust over time and our creation of new institutions (e.g. property rights), technological change (e.g. development of fusion energy) and substitution opportunities (e.g. alternative food sources) can all greatly change the value to society of a particular set of natural resources. In general, cconomists are more optimistic and positive about the environmental component of sustainable developmet than most biological scientists. [See Goeller and Weinberg (1976).]

Natural resources are often grouped into renewable or flow resources(fisheries, forests, natural 
populations, etc.) and non-renewable or stock resources (minerals, ctc.). For certain analytical purposes, this is a most convenient division.

In the case of renewable resources, a number of conservation or management strategies have been suggested by biologically trained scientists such as maximum sustainable yield (MSY) and optimum stocking rate or carrying capacity. Unfortunately, in practice, it is usually extremely difficult to implement these strategies with any degree of precision. Furthermore, they are not usually optimal in an economic sense. Normally, for cxample, the economic opumum level of use for a renewable resource will be less intensive that suggested by the MSY criteria. This is another instance where the paradigm of the economist is more constructive and positive with respect to the environmental component of sustainahility than the approaches advocated by ecologists and other biological scientists.

There is a world-wide need for mankind to develop appropriate management strategies for renewable resources such as soil, pastures, native forests, and native terrestrial and marine animal populations. In many parts of the world, over exploitation is causing irreversible changes. Renewable resources are becoming non-renewable. Appropriate management strategies can not be developed nor successfully implemented from a purely biological perspective. For example, new institutions which create appropriate economic and social incentive structures are usually required. To be relevant in the future, agricultural research will need to address these nonbiological constraints to the development of sustainable systems.

In the casc of non-renewable resources, questions about how and when they should be utilized raisc such issues as intergenerational equity, option values and resource stewardship. Indeed, even such fundamental philosophical questions as the rights of man versus the rights of other living creatures may also be raised.

None of the ideas and issues mentioned above are new. Yet, traditioral agricultural science edu- cation, based as it is on the basic biological and physical scinces, does not equip students to address these complex matters. Future training programs will need to recognize and remedy these deficiencics.

\section{Setting Research Prioritier and Getting "the right" Research Done}

Agricultural scientists have made great progress in the last 40 years in terms of raising agricu ltural output per unit of land and per unit of labour. A great deal of "the right" research must have been successfully undertaken. At the same time, enormous amounts of time and effort (money) have been devoted to "research" which has had no practical pay-off. A major part of the motivation for most research activity is the personal rewards it will bring to the researcher. Research administrators and policy-makcrs must be carcful to structure the reward system so that "appropriate" research is rewarded the most.

Unfortunately, traditional reward structures for agricultural researchers, especially those employed in publicly funded research institutions and universities, do not encourage people to address directly the complex problems associated with sus. tainable development. The long term, multi-disciplinary, non-scientific features of the problems in. volved "frighten" young, ambitious and capable agricultural scientists.

The challenge for research administrators of the future is how to attract the best researchers to these complex areas of research. Two major barriers to progress are the conventional disciplimary divisions between research groups and conventional wisdom among agrcultural scientists as to what constitutes "good research".

Researchers, like all human beings, prefer to work with and to receive the acceptance (accolades) of their peers. Consequently, research institutes and university departments tend to develop enclaves of scientists of like training (and hence values). Cross-fertilization of ideas is actively discouraged because the "best" journals in any field only accept 
research papers which maintain the traditional paradigm for that discipline. Future agricultural scientists will need to break down these disciplinary barriers if they are to undertake worthwhile research on the development of sustainable systems.

For most agricultural scientists, the personal need to be accepted as a scientist is in conflict their social responsibility to tackle the major sustainability problems facing agricultural industries. Agricultural educators and research policy/administrators need to be fully aware of this conflict. Unless this problem is addressed, the raison d'être for agricultural science education as distinct from a general scientific education, will disappear.

\section{Conclusions}

Sustainable agricultural development is like motherhood, no reasonahle person is opposed to the idea in principle. Yet in practice, much of modern agricultural output arises from production systems which appear to be unsustainable in the longer term.

Gradually, the future sustainability of large segments of world agriculture has become an important issue in many countries. Agricultural scientists who have played a major role in the development of modern agriculture over the last 40 years have been slow to recognize the new challenges ahead.

There are no easy solutions. However, the problems associated with sustainability are not amenable to purely scientific solutions. The economic and social dimensions are critical if meaningful progress is to be achieved.

Agricultural economics, farm management and rural sociology have been the poor cousins of the biological and physical science branches of agricultural science for the last 40 years. Yet, these social science disciplines can make major contributions towards a better understanding of how to develop and establish sustainable agricultural systems. Sustainability issues will require agricultural educators and research scientists of the 21st Century to place greater emphasis than has been the case in the past, on social and economic aspects of agricultural production.

\section{Reference}

Goeller, H.E. and A.M. Weinberg (1976). "The age of substitutability". Science. 191:683-89.

Nagy, I.G. and J.H. Sanders (1990). "Agricul tural technology development and dissemination within farming systems perspective". Agricultural Systems. 32:305-20.

Veeman, T.S. (1989). "Sustainable development: Its economic meaning and policy implications". $\mathrm{Ca}$ nadian Journal of Agricultural Economics. 37 (December): 875-86.

Yee, Y.L. and J.W. Longworth (1985). “Biases in research: The case of rubber growing in Malaysia". Journal of Agricultucal Economics. 36 (January): 15-29. 